WellBeing International

WBI Studies Repository

9-2011

\title{
The Efficacy of Three Types of Analgesic Drugs in Reducing Pain in the Rainbow Trout, Oncorhynchus mykiss
}

\author{
Jessica J. Mettam \\ University of Liverpool \\ Lois J. Oulton \\ University of Liverpool \\ Catherine R. McCrohan \\ University of Manchester \\ Lynne U. Sneddon \\ University of Liverpool
}

Follow this and additional works at: https://www.wellbeingintlstudiesrepository.org/acwp_vsm

Part of the Animal Studies Commons, Other Animal Sciences Commons, and the Veterinary

Toxicology and Pharmacology Commons

\section{Recommended Citation}

Mettam, J. J., Oulton, L. J., McCrohan, C. R., \& Sneddon, L. U. (2011). The efficacy of three types of analgesic drugs in reducing pain in the rainbow trout, Oncorhynchus mykiss. Applied Animal Behaviour Science, 133(3), 265-274.

This material is brought to you for free and open access by WellBeing International. It has been accepted for inclusion by an authorized administrator of the WBI Studies Repository. For more information, please contact wbisr-info@wellbeingintl.org.

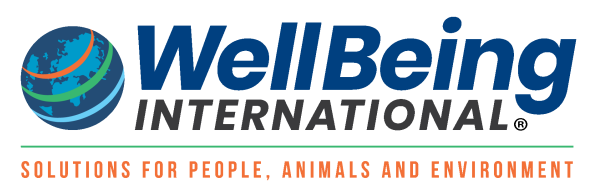




\title{
The Efficacy of Three Types of Analgesic Drugs in Reducing Pain in the Rainbow Trout, Oncorhynchus mykiss
}

\author{
Jessica J. Mettam ${ }^{1}$, Lois J. Oulton ${ }^{1}$, Catherine R. McCrohan ${ }^{2}$, Lynne U. Sneddon ${ }^{1,3}$ \\ ${ }^{1}$ University of Liverpool \\ ${ }^{2}$ University of Manchester \\ ${ }^{3}$ University of Chester
}

\section{KEYWORDS}

buprenorphine, carprofen, fish, lidocaine, nociception

\begin{abstract}
Recent research has shown the possibility of pain perception in fish; therefore, the use of analgesia or "painkillers" should be considered for invasive procedures. However, there is relatively little information on the effectiveness of analgesic drugs nor on the appropriate dose for fish. This study assessed the efficacy of three types of drug: an opioid, buprenorphine, a non-steroidal anti-inflammatory drug (NSAID), carprofen and a local anaesthetic, lidocaine. Each drug was tested at three doses on rainbow trout that were noxiously stimulated and the most effective dose was also given to fish experiencing no pain to investigate side-effects. Ventilation rate and time to resume feeding were used as pain indicators, together with the amount of activity and plasma cortisol concentrations to gauge any detrimental side effects. Buprenorphine at all three doses had limited impact on the fish's response to a painful stimulus. Carprofen ameliorated effects of noxious stimulation on time to resume feeding but activity was reduced more than by noxious treatment alone. Lidocaine reduced all of the pain indicators measured with the lowest, most effective dose being $1 \mathrm{mg}$ per fish. None of the analgesics led to raised plasma cortisol compared to control groups. This study demonstrates that lidocaine could be recommended for use in rainbow trout to ameliorate possible pain-related responses.
\end{abstract}

\section{Introduction}

Analgesics are administered in veterinary practice to alleviate pain in mammals, birds and reptiles (Fowler and Miller, 2003; Rang et al., 2007). They should be used preceding or following potentially painful surgical procedures and to reduce pain associated with chronic disease (Fowler and Miller, 2003). Despite the use of analgesia in other species, fish undergoing invasive procedures are generally not administered analgesia (Harms et al., 2005). The debate as to whether fish have the capacity to perceive pain has intensified since nociceptors that detect painful stimuli were identified in the rainbow trout, Oncorhynchus mykiss (Rose, 2002; Sneddon, 2002, 2004, 2009; Iwama, 2007). However, all authors agree that improving fish welfare is important regardless of whether they agree upon the question of fish 
experiencing pain (Rose, 2002; Iwama, 2007). If analgesics are shown to ameliorate adverse responses to a painful event, then their use should be recommended. A limited number of studies have investigated the effects of analgesics in fish, including morphine, butorphanol and ketoprofen (Sneddon, 2003a; Sneddon et al., 2003; Harms et al., 2005; Davis et al., 2006; Newby et al., 2006, 2007; Nordgreen et al., 2009). However, these drugs have been tested mainly in isolation and on individual species of fish.

Recent studies have not only demonstrated nociception in a teleost fish (Sneddon, 2002; Sneddon, 2003b; Ashley et al., 2006, 2007), but have also shown that fish display adverse behaviours following a noxious event, suggestive of pain and discomfort (Sneddon, 2003a; Reilly et al., 2008a; Ashley et al., 2009). These behavioural responses are reduced by morphine, an opioid analgesic, in rainbow trout (Sneddon, 2003a; Sneddon et al., 2003). Both ketoprofen, a non-steroidal anti-inflammatory drug (NSAID), and butorphanol, an opioid drug, have been used but of these two, only butorphanol was effective in reducing changes in post-surgical activity patterns in Koi carp, Cyprinus carpio (Harms et al., 2005) and neither were effective in reducing minimum anaesthetic concentrations in the chain dogfish, Scyliorhinus retifer (Davis et al., 2006), demonstrating the difficulty of extrapolating findings between species.

Some invasive procedures that are carried out routinely in aquaculture, fisheries and scientific experimentation, such as tagging and vaccination, could potentially be painful if they involve tissue damage (Hastein et al., 2005). In addition, veterinarians are increasingly asked to perform surgery on valuable, large ornamental fish, and it is possible that analgesic use could enhance the success of such interventions (Harms et al., 2005). Thus, determining analgesic protocols for use during invasive procedures could be of direct practical benefit by promoting recovery and increasing wellbeing. In addition, "modification of response to noxious stimuli by analgesics" is one of the eight criteria that an animal must fulfil to substantiate its capacity to perceive pain (Bateson, 1991). As there is still debate regarding whether fish are capable of conscious awareness of pain or merely demonstrate reflex reactions to noxious stimuli, a more thorough evaluation of whether or not analgesics affect a fish's response to a potentially painful event will provide constructive evidence for this discussion.

The aim of the present study was to assess the efficacy of three analgesics: an opiate (buprenorphine), an NSAID (carprofen) and a local anaesthetic (lidocaine). These agents were chosen because they are frequently used in other species, are readily available and represent the three major analgesic groups, thus covering a range of analgesic mechanisms. Three doses were tested for each drug; these were determined by extrapolation of dosage data from other species (humans and those animals routinely seen in veterinary practice). We tested the hypothesis that each drug would produce analgesia thereby reducing the responses to noxious and potentially painful stimulation. We expected that they would work in a dose dependent fashion with higher doses producing more pronounced analgesia. Rainbow trout were chosen as subjects owing to their commercial importance and because they are a validated model with the capacity for nociception and pain (Sneddon, 2002, 2003a, 2003b; Sneddon et al., 2003; Dunlop and Laming, 2005; Dunlop et al., 2006; Ashley et al., 2007, 2009; Newby and Stevens, 2008; Reilly et al., 2008a, 2008b). Subcutaneous injection of acetic acid was chosen as the noxious stimulus since this produces a prolonged behavioural and physiological response over 3 to $6 \mathrm{~h}$ in rainbow trout, that is reduced by administration of morphine (Sneddon, 2003a; Sneddon et al., 2003; Reilly et al., 2008a; Ashley et al., 2009). Previous studies have shown that these fish demonstrate significant changes in various behaviours (e.g. reduced swimming and activity, suspension of feeding, anomalous behaviours) and ventilation rate (indicator of stress) when exposed to a noxious stimulus (Sneddon, 2003a; Sneddon et al., 2003; Harms et al., 2005; Reilly et al., 2008a; Ashley et al., 2009). To determine drug efficacy and to identify possibly side-effects, we chose to monitor activity, time to resume feeding after treatment, ventilation rate and plasma cortisol concentration. Cortisol is used as an indicator of stress in fish as it is 
released during the primary stress response through activation of the hypothalamo-pituitary-interrenal (HPI) axis (Wendelaar Bonga, 1997). Similarly, in higher vertebrates glucocorticoid concentrations are commonly measured as indirect indicators during pain assessment (Rutherford, 2002). We expected that all indicators of pain, including the incidence of anomalous behaviours, increased ventilation rate and stress hormones, would be reduced with the use of analgesia.

\section{Materials and methods}

Experiments were carried out at the University of Liverpool using approved methods, working under provision of the Animals (Scientific Procedures) Act 1986, licensed by the Home Office, and following local ethics approval.

\subsection{Subjects and husbandry}

Female rainbow trout (mean size $111.2 \mathrm{~g} \pm 49.1 \mathrm{~g}$ ) were obtained from a commercial supplier (UK), and transferred to the aquarium in Liverpool. The use of females removed any confounding effects of gender on the study. Fish were housed in a stock tank ( $2 \mathrm{~m} \times 2 \mathrm{~m} \times 0.5 \mathrm{~m} ; \mathrm{n}=120$ fish per tank max), under a 12:12 h light:dark regime. This semiclosed system was maintained with a constant flow of filtered fresh water at $12 \pm 1 \circ \mathrm{C}$, and aeration provided via airline and an air stone linked to a compressed air supply. Fish were fed with a commercial trout feed (Skretting, Northwich, UK) at 1\% bodyweight per day.

After the fish had been allowed at least two weeks to recover from the stress of transport, they were carefully netted at random from the stock tank and transferred to individual glass observation tanks (45 $\mathrm{cm} \times 25 \mathrm{~cm} \times 35 \mathrm{~cm}$ ). One half of each tank was covered by dark, opaque material on the side, back and half of the top of the tank to provide a covered area for sheltering and to visually isolate the tanks. Each tank was provided with a gravel substrate, and a length of grey plastic pipe (approximately $15 \mathrm{~cm}$ long; 14 $\mathrm{cm}$ diameter) in the covered area as a refuge. The semi-closed system was maintained with a constant flow of aerated filtered fresh water at $12 \pm 1 \circ \mathrm{C}$, under a 12:12 h light:dark regime. The whole tank system was surrounded by a black curtain containing small observation holes, positioned $0.5 \mathrm{~m}$ from the tanks to prevent visual disturbance. Fish were fed commercial pellets, via a purpose-built dispenser, dropped at the same point in the uncovered tank area daily. In order to ensure that the fish were settled in the new environment experiments were only performed once a fish had been feeding consistently for at least three consecutive days.

\subsection{Treatment groups}

Three analgesics were tested: lidocaine (Sigma-Aldrich Co., UK), carprofen ("Rimadyl" Small Animal Solution for Injection, Pfizer Ltd., UK) and buprenorphine ("Temgesic", Schering-Plough, UK). Doses were determined by extrapolation of dosage data from other species (Fowler and Miller, 2003; Tennant, 2005). Fish were assigned to one of 14 treatment groups (Table 1; $n=5$ for each group; $n=70$ total): a control group given saline, which is non-noxious as demonstrated by previous studies which showed handled fish with no injection were identical in their responses to saline injected fish (Sneddon, 2003a; Sneddon et al., 2003); one group given acetic acid as a painful stimulus; nine groups given a combination of one analgesic at one of the three doses and acetic acid; and three further control groups given an analgesic alone at the most effective dose. The analgesic control group experiments were conducted at the end of the trials so that the dose used in the control groups could be determined according to which of the three trial doses appeared to be the most effective for each analgesic; this approach reduced the total number of animals used. 
Fish were caught by netting, anaesthetised by immersion in benzocaine dosed water $\left(0.033 \mathrm{~g} \mathrm{I}^{-1}\right.$, the benzocaine having first been dissolved in ethanol at $0.033 \mathrm{~g} \mathrm{I}^{-1}$; Sigma-Aldrich Co., UK), and weighed to the nearest $0.1 \mathrm{~g}$. Sub-cutaneous (s.c.) injections (of $0.1 \mathrm{ml}$ lidocaine and/or $0.1 \mathrm{ml}$ of $0.1 \%$ acetic acid or $0.1 \mathrm{ml}$ saline) were administered using a sterile $1 \mathrm{ml}$ syringe and needle $(25 \mathrm{~g})$, half into the upper frontal lip and half into the lower frontal lip. Lidocaine is a local anaesthetic and so we injected this into the same site as the acid, the frontal lips. For systemic analgesia, intramuscular (i.m.) injections of buprenorphine, carprofen or saline were injected into the muscle approximately $0.5 \mathrm{~cm}$ ventral to the dorsal fin on the left hand side using a sterile $1 \mathrm{ml}$ syringe and needle $(25 \mathrm{~g})$. The saline was used to control for any adverse responses to the intramuscular injection.

Table 1. Treatment groups designed to assess the effectiveness of the analgesics buprenorphine (B), carprofen (C) and lidocaine (L) in rainbow trout. Fish were assigned to one of 14 treatment groups ( $n=5$ for each group): saline control group (S), noxious acetic acid group (A), one of three analgesics (administered at three separate doses) plus acetic acid groups (BA, CA, LA), or to an analgesic and saline control group (BS, CS, LS). s.c. = subcutaneous injection of $0.1 \mathrm{ml}$ of each agent administered half into the upper and half into the lower frontal lips; i.m. = intramuscular injection into the muscle ventral to the dorsal fin. The concentration of acetic acid was $0.1 \%$ and sterile saline was $0.9 \% \mathrm{NaCl}$.

\begin{tabular}{|c|c|c|}
\hline \multirow[t]{2}{*}{ Group name } & \multicolumn{2}{|c|}{ Substances administered } \\
\hline & s.c. & i.m. \\
\hline S & Saline & Saline \\
\hline A & Acid & Saline \\
\hline $0.01 B A$ & Acid & Buprenorphine $\left(0.01 \mathrm{mg} \mathrm{kg}^{-1}\right)$ \\
\hline 0.05BA & Acid & Buprenorphine $\left(0.05 \mathrm{mg} \mathrm{kg}^{-1}\right)$ \\
\hline $0.10 \mathrm{BA}$ & Acid & Buprenorphine $\left(0.10 \mathrm{mg} \mathrm{kg}^{-1}\right)$ \\
\hline $0.01 B S$ & Saline & Buprenorphine $\left(0.01 \mathrm{mg} \mathrm{kg}^{-1}\right)$ \\
\hline $1.0 \mathrm{CA}$ & Acid & Carprofen $\left(1.0 \mathrm{mg} \mathrm{kg}^{-1}\right)$ \\
\hline $2.5 \mathrm{CA}$ & Acid & Carprofen $\left(2.5 \mathrm{mg} \mathrm{kg}^{-1}\right)$ \\
\hline $5.0 \mathrm{CA}$ & Acid & Carprofen $\left(5.0 \mathrm{mg} \mathrm{kg}^{-1}\right)$ \\
\hline $5.0 \mathrm{CS}$ & Saline & Carprofen $\left(5.0 \mathrm{mg} \mathrm{kg}^{-1}\right)$ \\
\hline $0.5 \mathrm{LA}$ & Acid and lidocaine (0.5 mg/fish) & --- \\
\hline 1.OLA & Acid and lidocaine (1.0 mg/fish) & --- \\
\hline 2.0LA & Acid and lidocaine (2.0 mg/fish) & --- \\
\hline 1.0LS & Saline and lidocaine (1.0 mg/fish) & --- \\
\hline
\end{tabular}




\subsection{Data collection}

Fish were filmed over the entire experiment using low light level video cameras, which were set up behind the curtain at least $1 \mathrm{~h}$ prior to recording to allow the fish to habituate to their presence. Fish behaviour was recorded onto VHS tape and then scored blind using the Hindsight programme (Hindsight for MSDOS, Ethological Recording and Analysis Software 1993-1996, Scott Weiss).

Prior to treatment, the duration of activity (time (s) excluding being motionless or making small movements less than $1 \mathrm{~cm}$ measured using externally placed rulers vertically and horizontally $(0.5 \mathrm{~cm}$ increments) at the front of the tank) and ventilation rate (operculum beats/min) of each fish were recorded for 15 min to obtain baseline data (pre-treatment behaviour and ventilation) with which to compare posttreatment levels. Fish were then randomly assigned to one of the treatment groups. Each fish was injected individually, allowed 30 min to recover, and then offered 4 food pellets via the dispenser to see if it resumed feeding and ingested a pellet (this was done from behind the surrounding curtain to limit any visual disturbance). Ventilation rate and activity were then recorded as for pretreatment. Observations were repeated every $30 \mathrm{~min}$ for $3 \mathrm{~h}$ since it is known that the effects of a $0.1 \%$ acetic acid injection persist for up to $3 \mathrm{~h}$ (Sneddon, 2003a; Sneddon et al., 2003). At the end of the experiment, fish were euthanized using a Schedule 1 method (concussion followed by exsanguination), and a blood sample taken from the caudal vein (using a sterile heparinised $25 \mathrm{~g}$ needle and $2 \mathrm{ml}$ syringe) for plasma cortisol analysis (carried out blind at an independent laboratory using a validated radioimmunoassay; Pottinger and Carrick, 2001). Experiments were carried out at the same time each day (commencing at $12 \mathrm{pm} \mathrm{GMT),} \mathrm{to} \mathrm{minimise} \mathrm{any}$ effect of diurnal fluctuation in the plasma cortisol of the fish (Wendelaar Bonga, 1997).

The data were either not normally distributed or non-parametric; therefore, non-parametric tests were employed. To determine the effects of acid (A) on trout behaviour and physiology Mann-Whitney $U$ tests were used to identify any differences in ventilation rate and recovery rate, duration of activity, at 30 and $180 \mathrm{~min}$, and plasma cortisol concentrations compared with saline injected fish (S) and Wilcoxon signed rank tests were used to compare pre-treatment values with 30 and 180 min post treatment values with $S$ and $A$ groups. Ventilation rate of recovery per minute was calculated, from $30 \mathrm{~min}$ to $180 \mathrm{~min}$ after the treatment for each group giving one value per fish. Chi-squared goodness of fit tests with Yate's correction were used to determine if treatment affected the time to resume feeding since these were categorical data. To analyse the efficacy of each analgesic and determine the most effective dose, they were compared with the saline group since the most effective analgesic should not differ from the saline injected fish. The time points of 30 and $180 \mathrm{~min}$ after treatment were chosen for analysis, as $30 \mathrm{~min}$ reflects the most intense effects of the treatment and the 180 min data indicate recovery, as observed in previous studies on rainbow trout (Fig. 2A; Sneddon, 2003a). Ventilation rates of recovery were analysed with Kruskal-Wallis tests to determine any differences between each of the groups within an analgesic compared with saline controls, and, where appropriate, post hoc Mann-Whitney $U$ comparisons were made to compare each of the treatment groups to the $\mathrm{S}$ control group. Cortisol data were analysed using Kruskal-Wallis tests to determine any differences in plasma concentration between all groups. The amount of time spent active was analysed for differences between the analgesic groups and $\mathrm{S}$ controls using Kruskal-Wallis tests. Wilcoxon signed rank tests were used to compare each treatment group to its pre-treatment level at 30 and $180 \mathrm{~min}$. Chi squared goodness of fit test was used to determine the effects of each analgesic dose on the time to resume feeding.

Differences between the three analgesics were assessed by comparing the analgesic plus acid groups at the doses considered most effective for each analgesic with the saline group (4 groups in all). Ventilation rates (30 and $180 \mathrm{~min}$ ), rates of recovery of ventilation, plasma cortisol, and time spent active (30 and $180 \mathrm{~min}$ ) after treatment were analysed using Kruskal-Wallis tests and, where appropriate, post hoc 
Mann-Whitney $U$ comparisons. All statistics were calculated using two-tailed tests throughout with correction factors used where appropriate, using SPSS Version 14 or Version 15.

Fig. 1. The median percentage ( $\pm I Q R)$ change in activity from pretreatment (baseline) values at (A) 30 min and (B) $180 \mathrm{~min}$ after rainbow trout were injected with saline, acid, buprenorphine and acid (BA), carprofen and acid (CA), lidocaine and acid (LA) or one of the three analgesics and saline (BS, CS, LS). Dose of analgesic is given ( $\mathrm{mg} \mathrm{kg}^{-1}$ or per fish) next to the appropriate label $(a=P<0.05$ compared with pre-treatment activity using Wilcoxon analysis; $b=$ $\mathrm{P}<0.05$ compared with saline using Mann-Whitney $U$ analysis; $n=5$ per group).

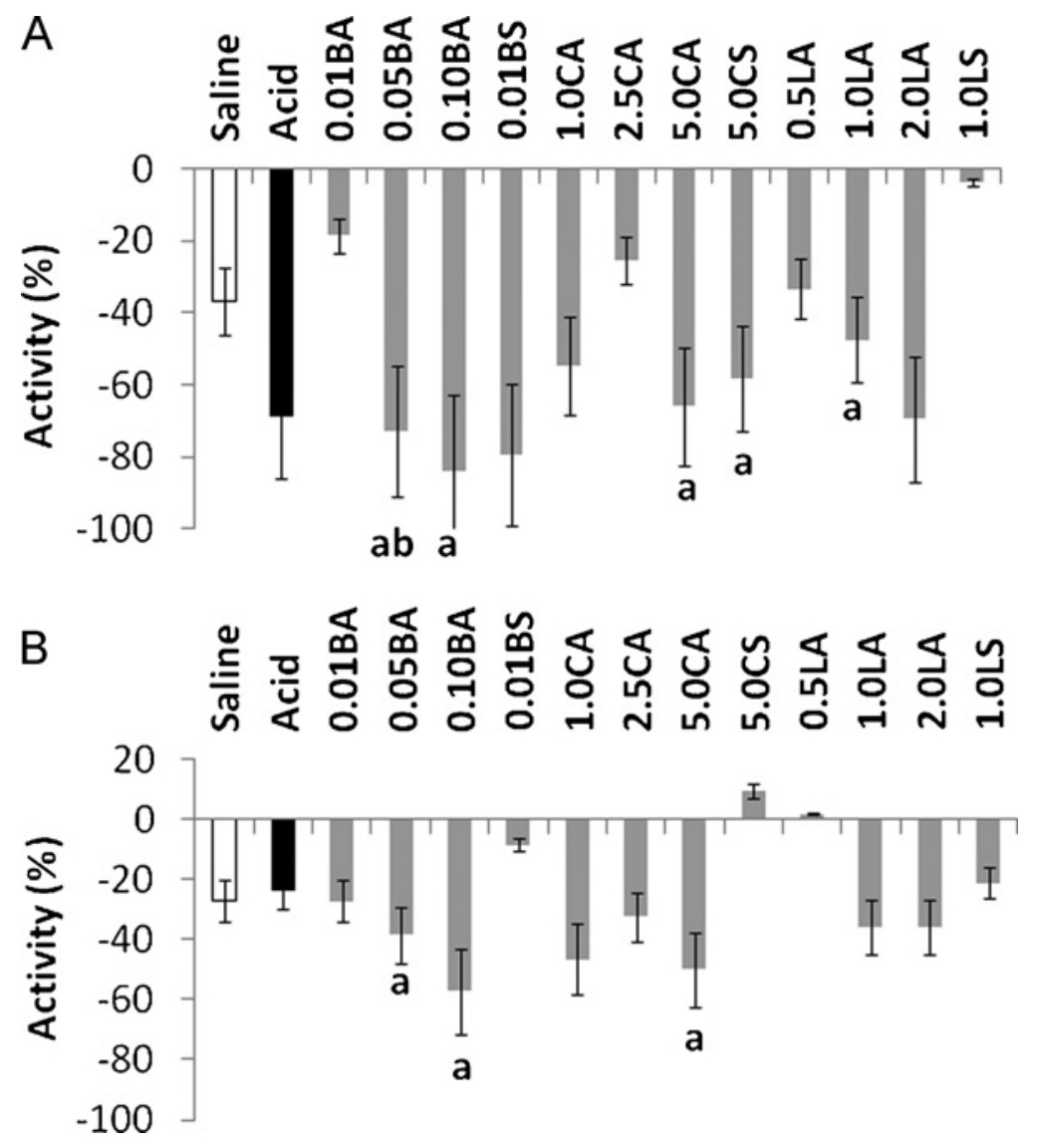

\section{Results}

\subsection{Effects of acid alone}

Differences in ventilation rate, activity and time to resume feeding were observed between fish injected with saline (S) and those treated with acetic acid (A). Fish in the A group had significantly higher ventilation rates (Fig. 2A; $U=2.193, P=0.028$ ) than those in the $S$ group. Group A fish also exhibited a longer latency to resume feeding $(P=0.001 ;$ Table 2$)$. In addition, reduced activity compared to pretreatment was shown in group $A$ fish $(\mathrm{W}=-2.50, \mathrm{P}=0.01)$, but not in group $\mathrm{S}$ fish. There were no significant differences between the $\mathrm{S}$ and $\mathrm{A}$ groups in the plasma cortisol concentrations at the end of the experiment $(U=0.522, P=0.602)$. 


\subsection{Effects of analgesics on behaviour}

\subsubsection{Time to resume feeding}

Fish in the $\mathrm{S}$ group all resumed feeding by the 30 min time point whereas the other treatment groups took variable times to resume feeding (Table 2). None of the buprenorphine doses had a positive effect on the resumption of feeding. However, carprofen and lidocaine treated fish resumed feeding at similar times to the saline controls, except those fish given the lowest doses (1.0CA and 0.5LA), which took longer to resume feeding (Table 2).

\subsubsection{Duration of activity}

There was a difference in the duration of activity between the buprenorphine treated groups compared with the $\mathrm{S}$ controls at $30 \mathrm{~min}$ (Fig. $1 ; \mathrm{H}=10.036$, d.f. $=4, \mathrm{P}=0.040$ ), with all groups having similar activity levels to the $S$ group except group 0.05BA $(U=-1.984, P=0.047)$ which had lower activity. By 180 min activity was similar in buprenorphine and $S$ groups $(H=6.372$, d.f. $=4, P=0.173)$. However, at both 30 min and 180 min activity was significantly lower in groups 0.05BA and 0.10BA compared with pretreatment levels (Fig. 1; $\mathrm{W}=2.023, \mathrm{P}=0.043$ at 30 and $180 \mathrm{~min}$ ). Carprofen treated groups had similar activity values compared to $\mathrm{S}$ controls at $30 \mathrm{~min}(\mathrm{H}=6.609$, d.f. $=4, \mathrm{P}=0.158)$ and at $180 \mathrm{~min}(\mathrm{H}=$ 3.729 , d.f. $=4, P=0.444)$. However, at 30 min activity was significantly lower than pre-treatment levels in groups 5.0CA and 5.0CS (Fig. 1; $W=2.023, P=0.043$ ), and in group 5.0CA the time spent active was still lower than pre-treatment levels at $180 \mathrm{~min}(\mathrm{~W}=2.023, \mathrm{P}=0.043)$ showing a prolonged side-effect of this dose. Comparisons between the lidocaine treated groups and saline controls did not reveal any differences between the groups either at 30 (Fig. $1 ; \mathrm{H}=5.147$, d.f. $=4, \mathrm{P}=0.273$ ) or at $180 \mathrm{~min}(\mathrm{H}=$ 1.194 , d.f. $=4, P=0.879$ ). However, at $30 \mathrm{~min}$ a significant reduction in activity was observed in group 1.0LA in comparison with pre-treatment $(\mathrm{W}=2.023, \mathrm{P}=0.043)$, but by $180 \mathrm{~min}$ activity in this group had recovered towards baseline activity.

\subsection{Analgesic effects on physiology}

\subsubsection{Plasma cortisol}

There were no significant differences between the plasma cortisol concentrations in any of the buprenorphine treated groups $(H=5.258$, d.f. $=5, P=0.385)$, nor the carprofen treated groups $(H=$ 7.117, d.f. $=5, P=0.212$ ) compared with the saline and acid groups. However, there was a trend for plasma cortisol to be lower in the lidocaine groups, 1.0LA and 1.0LS $(H=11.039$, d.f. $=5, P=0.051)$.

\subsubsection{Ventilation rate}

At 30 min after treatment, all buprenorphine treated groups had higher ventilation rates than their pretreatment levels (Fig. 2B; $\mathrm{W}=2.023, \mathrm{P}=0.043$ for all groups). Ventilation rates differed between the groups at this time point $(H=15.303$, d.f. $=4, P=0.004)$; where most groups had higher ventilation rates than the $\mathrm{S}$ group (0.01BA $U=-2.627, \mathrm{P}=0.009 ; 0.05 \mathrm{BA} U=-2.627, \mathrm{P}=0.009 ; 0.01 \mathrm{BS} \mathrm{U}=-2.102, \mathrm{P}=$ 0.036 ) except group 0.1BA $(U=-1.781, P=0.075)$. By 180 min most groups had recovered, with only group 0.01BA having a significantly higher ventilation rate than pre-treatment (Fig. $2, P=0.043$ ). There was no difference in ventilation rate between the buprenorphine treated groups and $\mathrm{S}$ controls at $180 \mathrm{~min}$ (Fig. 2C; $\mathrm{H}=6.375$, d.f. $=4, \mathrm{P}=0.173$ ).

All carprofen treated groups also had higher ventilation rates at 30 min post-treatment compared to pretreatment (Fig. 2B; 1.0CA W $=2.032, \mathrm{P}=0.042 ; 2.5 \mathrm{CA} \mathrm{W}=2.023, \mathrm{P}=0.043 ; 5.0 \mathrm{CA} \mathrm{W}=2.032, \mathrm{P}=$ $0.042 ; 5.0 C S W=2.023, P=0.043)$. Overall ventilation rate differed between the groups $(H=15.699$, d.f. 
$=4, \mathrm{P}=0.003)$, where all carprofen treated groups had higher ventilation rates in comparison with the $\mathrm{S}$ group (1.0CA $U=2.619, \mathrm{P}=0.009 ; 2.5 \mathrm{CA} U=2.627, \mathrm{P}=0.009 ; 5.0 \mathrm{CA} \mathrm{U}=2.619, \mathrm{P}=0.009 ; 5.0 \mathrm{CS} \mathrm{U}=$ $2.227, P=0.026)$. By $180 \mathrm{~min}$, rates in these groups recovered towards pre-treatment levels, and only the ventilation rate of group 5.0CS remained high $(\mathrm{W}=2.023, \mathrm{P}=0.043)$. By this time point carprofen groups had similar ventilation rates to the $\mathrm{S}$ controls (Fig. $2 \mathrm{C} ; \mathrm{H}=5.485$, d.f. $=4, \mathrm{P}=0.241$ ).

Similarly, ventilation rate increased in all lidocaine treated groups at 30 min post-treatment in comparison with pre-treatment levels (Fig. 2B, 0.5LA U $=2.032, \mathrm{P}=0.042 ; 1.0 \mathrm{LA} U=2.041, \mathrm{P}=0.041 ; 2.0 \mathrm{LA} U=$ $2.023, P=0.043 ; 1.0 L S U=4.785, P<0.01)$. However, there was no difference in ventilation rate between the groups and saline at this time point $(H=4.453$, d.f. $=4, P=0.348)$. By $180 \mathrm{~min}$, rates in all groups recovered towards pre-treatment levels except group $0.5 \mathrm{LA}(\mathrm{W}=2.023, \mathrm{P}=0.043)$. At $180 \mathrm{~min}$ there was no difference in ventilation rate between the groups (Fig. $2 \mathrm{C} ; \mathrm{H}=5.657$, d.f. $=4, \mathrm{P}=0.226$ ).

When considering the rate of recovery in ventilation rate between 30 and 180 min post-treatment, buprenorphine groups differed from the $S$ group (Fig. 3; $\mathrm{H}=13.543$, d.f. $=4, \mathrm{P}=0.009$ ). Recovery rates in groups 0.05BA $(U=-2.514, P=0.012)$ and 0.10BA $(U=-1.984, P=0.047)$ were higher than $S$ fish, whereas fish in groups 0.01BA and group 0.01BS had similar rates $(0.01 \mathrm{BA}, U=-1.257, \mathrm{P}=0.209$; $0.01 \mathrm{BS}, \mathrm{U}=-0.524, \mathrm{P}=0.60$; Figs. $2 \mathrm{~B}$ and 3 ). Rate of recovery did not differ between the carprofen treated groups (Fig. 3; $\mathrm{H}=8.588$, d.f. $=4, \mathrm{P}=0.072$ ), nor between lidocaine treated fish when compared with $\mathrm{S}$ controls (Fig. 3; $\mathrm{H}=5.293$, d.f. $=4, \mathrm{P}=0.259$ ).

Table 2. Chi-squared $\left(X^{2}\right)$ analysis of the time to resume feeding. Contingency table showing the number of fish that resumed feeding at each time point after the treatment: saline (S); acid (A); buprenorphine and acid (dose/kg BA); buprenorphine and saline (BS); carprofen and acid (dose/kg CA); carprofen and saline (CS); lidocaine and acid (dose/fish LA) and lidocaine and saline (LS) as described in Table $1(n=5$ for each group; NS = not significant, i.e. no skew towards early feeding).

\begin{tabular}{|c|c|c|c|c|c|c|c|c|}
\hline & & Numbe & fish eat & at time & t $(\min )$ & & $x^{2}$ value & D value \\
\hline & 30 & 60 & 90 & 120 & 150 & 180 & & $r$ value \\
\hline$S$ & 5 & 0 & 0 & 0 & 0 & 0 & 26.8 & 0.001 \\
\hline A & 3 & 1 & 0 & 1 & 0 & 0 & 9.99 & NS \\
\hline $0.01 B A$ & 1 & 3 & 0 & 0 & 0 & 1 & 9.99 & NS \\
\hline $0.05 B A$ & 3 & 0 & 1 & 0 & 0 & 1 & 9.99 & NS \\
\hline $.0 B A$ & 2 & 1 & 2 & 0 & 0 & 0 & 7.59 & NS \\
\hline $0.01 B S$ & 2 & 2 & 0 & 1 & 0 & 0 & 7.59 & NS \\
\hline $1.0 \mathrm{CA}$ & 3 & 0 & 1 & 0 & 0 & 1 & 9.99 & NS \\
\hline $2.5 \mathrm{CA}$ & 4 & 0 & 0 & 0 & 1 & 0 & 17.2 & 0.01 \\
\hline $5.0 \mathrm{CA}$ & 5 & 0 & 0 & 0 & 0 & 0 & 26.8 & 0.001 \\
\hline $5.0 \mathrm{CS}$ & 4 & 1 & 0 & 0 & 0 & 0 & 17.2 & 0.01 \\
\hline $0.5 \mathrm{LA}$ & 2 & 0 & 2 & 0 & 0 & 1 & 7.59 & NS \\
\hline 1.0LA & 3 & 0 & 2 & 0 & 0 & 0 & 12.4 & 0.05 \\
\hline 2.0LA & 4 & 1 & 0 & 0 & 0 & 0 & 17.2 & 0.01 \\
\hline $1.0 \mathrm{LS}$ & 5 & 0 & 0 & 0 & 0 & 0 & 26.8 & 0.001 \\
\hline Expected values & 0.833 & 0.833 & 0.8773 & 0.833 & 0.833 & 0.833 & --- & --- \\
\hline
\end{tabular}


Fig. 2. A. The median ventilation rate (opercular beat rate per $\mathrm{min}, \mathrm{OBR}$ ) of the saline and acid injected groups illustrating the baseline measurements $(0 \mathrm{~min})$, the highest rates at $30 \mathrm{~min}$ and recovery at $180 \mathrm{~min}(\mathrm{n}=5 \mathrm{per}$ group). The median percentage $( \pm \mathrm{IQR})$ change in ventilation rate from pre-treatment values at $(B) 30 \mathrm{~min}$ and $(\mathrm{C}) 180 \mathrm{~min}$ after rainbow trout were injected with saline, acid, buprenorphine and acid (BA), carprofen and acid (CA), lidocaine

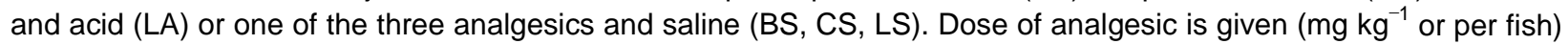
next to the appropriate label $(\mathrm{a}=\mathrm{P}<0.05$ compared with pre-treatment ventilation; $\mathrm{b}=\mathrm{P}<0.05$ compared with saline; $\mathrm{n}=5$ per group).
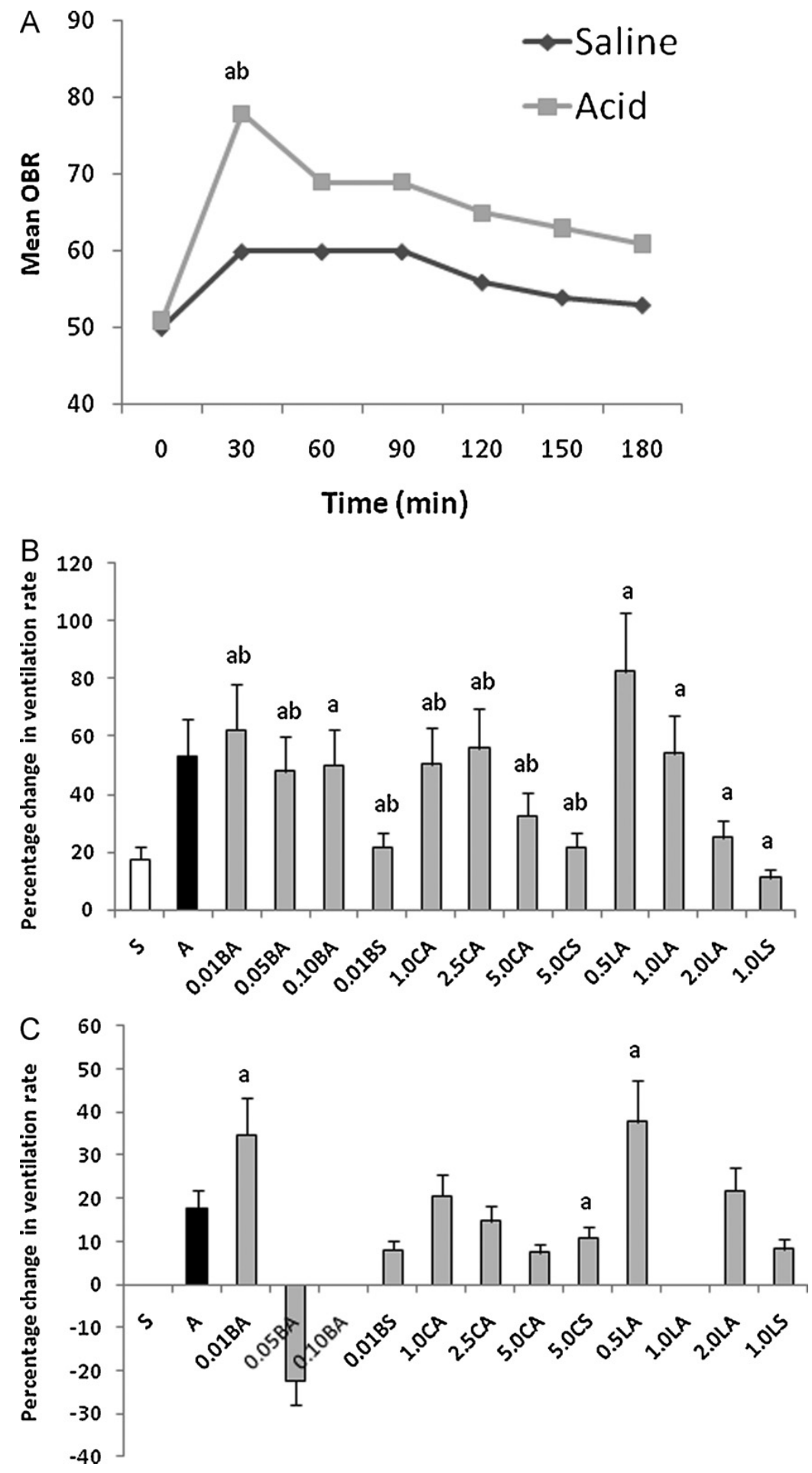


\subsection{Comparison between the three analgesic drugs}

The doses considered most effective from the previous analysis (0.01BA, 5.0CA and 1.0LA) were compared with the $S$ group to determine which of the drugs tested provided the most effective antinociceptive or analgesic effect, such that it was no different from non-noxious stimulation. There was no difference in the time spent active between the three analgesic groups at $30(\mathrm{H}=4.05$, d.f. $=3, \mathrm{P}=0.256)$ and $180 \mathrm{~min}(\mathrm{H}=2.46$, d.f. $=3, \mathrm{P}=0.482)$. At $30 \mathrm{~min}$ there was a significant difference in ventilation rate between the groups $(H=14.58$, d.f. $=3, P=0.002)$, with all treatment groups having higher ventilation rates than the $\mathrm{S}$ group except for the lidocaine treated group (0.01BA $U=-2.63, P=0.008 ; 5.0 \mathrm{CA} \mathrm{U}=$ $-2.619, \mathrm{P}=0.008 ; 1.0 \mathrm{LA} U=-0.105, \mathrm{P}=1.0$ ). By $180 \mathrm{~min}$ the buprenorphine treated group still had higher ventilation rates than the $S$ group (0.01BA $U=-2.65, P=0.008)$. In contrast, the carprofen and lidocaine groups were similar to the $S$ group (5.0CA $U=-1.89, P=0.056 ; 1.0 L A U=-1.37, P=0.222)$. Nor was there a difference when comparing plasma cortisol concentration $(H=2.79$, d.f. $=3, P=0.424)$.

\section{Discussion}

Noxious treatment (injection of acid) resulted in increased ventilation rates and a reduction in time spent active compared to saline-injected controls. Acid treated fish (A) also took longer to resume feeding. These results are similar to those of previous studies and are suggestive of a complex behavioural response to the noxious stimulus (Sneddon, 2003a; Reilly et al., 2008a). Buprenorphine (B) treatment had limited effect on the fishes' response to the noxious treatment. None of the doses reduced the suspension of feeding behaviour or the accompanying decrease in activity. Carprofen (C) appeared to have some analgesic or anti-nociceptive effect, as treatment with both $2.5 \mathrm{mg} \mathrm{kg}^{-1}$ and $5.0 \mathrm{mg} \mathrm{kg}^{-1}$ reduced the suspension in feeding behaviour. However, $\mathrm{C}$ treatment did not have any beneficial effect on activity; indeed, fish in both the acid treated (CA) and saline (CS) treated $5.0 \mathrm{mg} \mathrm{kg}^{-1}$ carprofen groups spent less time active than fish in the acid alone group, possibly indicating an unwanted side effect of $\mathrm{C}$. In addition, $\mathrm{C}$ treated groups had higher ventilation rates than fish in the $\mathrm{S}$ control group. The higher doses of lidocaine $(\mathrm{L})$ appeared to act as an analgesic or anti-nociceptive since fish treated with both 1.0 $\mathrm{mg}$ and $2.0 \mathrm{mg}$ of $\mathrm{L}$ had similar ventilation rates, activity and resumed feeding at comparable times to the $S$ control group. In comparisons between the analgesics, the $1.0 \mathrm{mg}$ dose of $L$ was the only drug to show significant benefit for all of the parameters measured. Therefore, this dose of lidocaine was deemed the most effective of the drugs tested.

\subsection{Effects of acid}

Previous studies in rainbow trout found that increased ventilation rate immediately following noxious stimulation was one of the most marked effects of noxious stimulation (Sneddon, 2003a; Sneddon et al., 2003; Reilly et al., 2008a; Ashley et al., 2009; Newby et al., 2009). The present result confirms this, suggesting that ventilation rate is a useful indicator of nociception or pain perception in the rainbow trout. Reduced activity in response to a noxious stimulus has been recorded in Koi carp, zebrafish (Danio rerio) and trout (Harms et al., 2005; Reilly et al., 2008a; Ashley et al., 2009) as well as in non-fish species (Gentle and Hill, 1987; Roughan and Flecknell, 2000; Underwood, 2002; Walker et al., 2009). Such reductions in activity could be viewed as a protective, vegetative response to prevent further injury and aid recovery. However, changes in activity level suggest a complex behavior rather than a reflex reaction (Gentle and Hill, 1987), indicating higher brain processing that may control decision making. In the present study, feeding was suspended following acid administration. Reduced appetite can be a clinical sign of pain (Bateson, 1991; Mayer, 2007), and increased latency to feeding has been found in previous studies assessing the effects of acetic acid on trout behaviour (Sneddon, 2003a; Sneddon et al., 2003). 
Plasma cortisol concentrations were not elevated by noxious treatment, as previously reported by Ashley et al. (2009) in rainbow trout. Considerable individual variation was seen in plasma cortisol within all groups. Studies have shown that cortisol concentrations in fish vary, and are dependent upon individual status such as stress coping style where divergent stress responses have been recorded (Overli et al., 1999; Thomson et al., 2011). Therefore, differences may not have been observed here owing to the relatively low sample sizes, which were chosen based on ethical considerations. However, none of the analgesics resulted in higher plasma cortisol, suggesting that they may not cause a physiological stress response.

Fig. 3. The median $( \pm \mid Q R)$ rate of recovery in opercular beat rate over the experimental period (30-180 min) after rainbow trout were injected with saline, acid, buprenorphine and acid (BA), carprofen and acid (CA), lidocaine and acid (LA) or one of the three analgesics and saline (BS, CS, LS). Dose of analgesic is given ( $\mathrm{mg} \mathrm{kg}^{-1}$ or per fish) next to the appropriate label ( $\mathrm{a}=\mathrm{P}<0.05$ compared with saline; $\mathrm{n}=5$ per group).

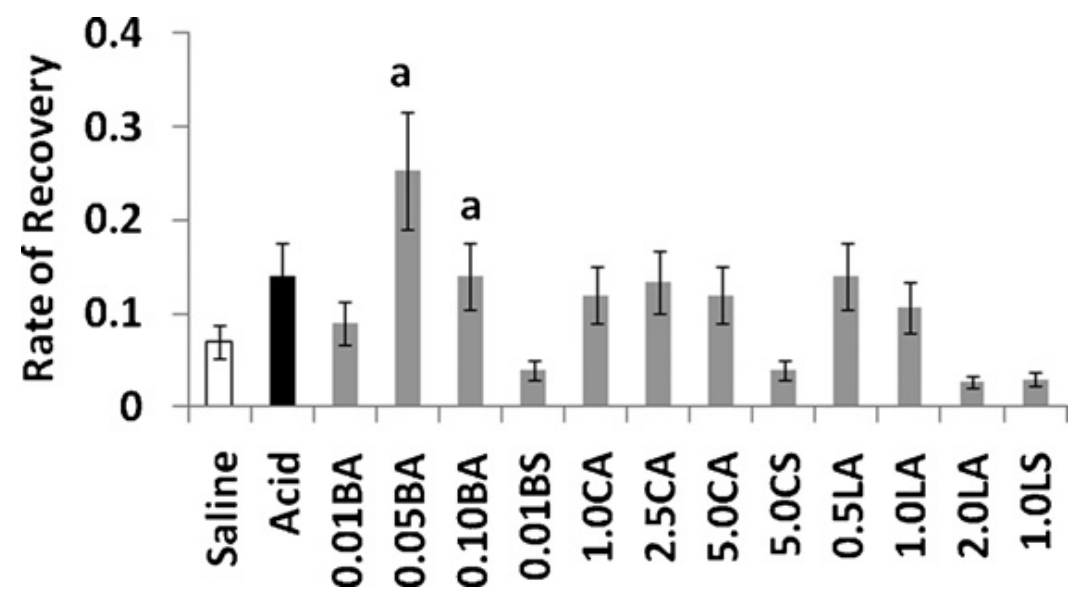

\subsection{Buprenorphine}

Overall, buprenorphine (B) treatment showed minimal analgesic or anti-nociceptive actions. The only dose to have a positive effect on ventilation rate was $0.1 \mathrm{mg} \mathrm{kg}^{-1}$; fish in this group demonstrated a lower ventilation rate at $30 \mathrm{~min}$ after treatment. The fact that ventilation rates were not generally lower in $\mathrm{B}$ treated fish could be considered surprising as opioids tend to induce respiratory depression in humans, even at therapeutic doses (Rang et al., 2007). However, B is thought to produce less respiratory depression than other opioids (Papich, 2007) and in non-primates therapeutic doses of opioids do not cause marked respiratory depression (Grant, 2006; Wagner, 2009). Newby et al. (2007) found that administration of a high dose of morphine did not alter respiratory rate in winter flounder (Pseudopleuronectes americanus) and Sneddon (2003a) reported that administration of morphine did not affect the respiratory rate of trout. Thus, it is possible that opiates do not cause respiratory depression in fish. The impact of such drugs on ventilation rate and its usefulness as an indicator of analgesic effect need further investigation.

All B groups, including the saline control group, took significantly longer to resume feeding than the saline alone control group, suggesting that not only did the drug not have an anti-nociceptive or analgesic effect, but that in itself it produced adverse effects. Decreased appetence may occur as a general response to stress (Bernier, 2006), but opioids are also known to directly cause gastrointestinal side-effects (Grant, 2006; Wagner, 2009). However, Sneddon's (2003a) study found that fish treated with morphine resumed feeding as rapidly as control fish, and in the study by Harms et al. (2005) another opioid, butorphanol, had 
no apparent adverse effects on feeding, indicating that gastrointestinal side effects of opioids might not be an issue in fish. The possibility that buprenorphine use might inhibit feeding could be a factor to consider if this drug was ever used in circumstances where rapid resumption of feeding in experimental studies was required. The discrepancy in disruption to feeding caused by these drugs and findings from fish studies should be explored particularly in using latency to feed as an indicator of the efficacy of analgesics.

The higher doses of B reduced activity, even when administered alone. Buprenorphine can have a sedative action in mammals (Glennon and Jeffs, 2001; Rang et al., 2007) and it may be that at higher doses the behavior of the fish was influenced by sedation so that activity was reduced. If this was the case then it would appear that the effects of the lowest dose were diminished by the end of the experimental time period whereas the higher doses of buprenorphine still reduced activity after 180 min. Again this detrimental impact upon activity may be an undesirable side-effect in behavioural studies.

\subsection{Carprofen}

Treatment with the two higher doses of carprofen (C) had a beneficial effect on the time taken to resume feeding, suggesting anti-nociceptive or analgesic properties in the trout. NSAIDs exert their effects through inhibition of arachidonate cyclo-oxygenase (COX) enzymes to reduce inflammation and depress afferent pain fibre transmission. COX enzymes have been identified in a teleost (Grosser et al., 2002; Teraoka et al., 2009), and a study by Harms et al. (2005) demonstrated a beneficial effect of ketoprofen on reducing inflammation in carp; therefore, $\mathrm{C}$ was expected to have some efficacy in fish.

When $\mathrm{C}$ was administered in combination with saline (CS), fish demonstrated higher ventilation rates than when given saline alone (S), possibly reflecting a stress response elicited by $C$. This drug did not ameliorate changes in activity induced by acetic acid (A), and carprofen alone (CS) at $5.0 \mathrm{mg} \mathrm{kg}^{-1}$ resulted in a decrease in activity. This effect on activity was not seen at $2.5 \mathrm{mg} \mathrm{kg}^{-1}$, so although the 5.0 $\mathrm{mg} \mathrm{kg}^{-1}$ dose was used in the control study the $2.5 \mathrm{mg} \mathrm{kg}^{-1}$ dose demonstrated the more beneficial effect overall.

It is possible that the doses used in the present experiment were not high enough to provide complete anti-nociception or analgesia. They were chosen based on those routinely used in mammalian veterinary practice but a study on $\mathrm{C}$ analgesia in chickens exposed to an acute noxious stimulus found that observable behavioural effects only occurred above $30 \mathrm{mg} \mathrm{kg}^{-1}$ (Hocking et al., 2005). However, studies on the effects of $C$ on chronically lame chickens found doses of $1 \mathrm{mg} \mathrm{kg}-1$ and $4 \mathrm{mg} \mathrm{kg}-1$ to be effective (McGeown et al., 1999; Danbury et al., 2000). Nonetheless, there are significant species differences in the pharmacokinetics of NSAIDs (Hocking et al., 2005; Grant, 2006), and assessment of the pharmacokinetics of carprofen (and other NSAIDs) could be helpful in the determination of suitable dosing regimes for fish.

Carprofen treatment did not affect cortisol concentrations, but the apparent negative effect of the highest dose on activity does suggest that further testing is advisable. Adverse side effects of NSAIDs in species other than fish tend to be more of an issue with their long term use rather than in acute treatment (Grant, 2006; Budsberg, 2009). The two higher doses (2.5 and $5.0 \mathrm{mg} \mathrm{kg}-1$ ) were the most effective, but the 5.0 $\mathrm{mg} \mathrm{kg}^{-1}$ dose adversely affected activity. Further work is needed to determine all the possible factors related to NSAID efficacy in fish to be able to reliably use carprofen as an analgesic. 


\subsection{Lidocaine}

The two higher doses of lidocaine $(L)$ had a positive effect on all of the indicators measured. Although the $2 \mathrm{mg}$ dose appeared to have the more beneficial effect on cortisol concentrations, administration of $1 \mathrm{mg}$ was deemed most effective as fish given this dose exhibited faster physiological and behavioural recovery. Local anaesthetics are usually administered to a specific area, but ultimately they are absorbed systemically. Cortisol levels were unaffected by $L$ treatment alone (LS) compared with $S$ controls; therefore, it does not appear to induce a stress response in trout under these experimental conditions. As no side effects were observed it would indicate that the higher doses tested were within the therapeutic range of the drug. Therefore, $L$ can be recommended as an effective anti-nociceptive or analgesic in trout exposed to an acute noxious stimulus with the $1.0 \mathrm{mg}$ dose of $L$ the most effective of the three doses tested.

Based on parameters measured in this study, comparisons between the different analgesics revealed that $L$ was the most effective of the three drugs. Local anaesthetics are used in mammals to provide localized analgesia, and so the effectiveness of lidocaine in alleviating responses to localised acid stimulus enables direct comparisons with this drug's use in higher vertebrates (Grant, 2006; Ashley, 2007; Rang et al., 2007; Mama, 2009). Although $L$ has been studied as an anaesthetic (Carrasco et al., 1984; Park et al., 2009), this is the first study to assess its use as an analgesic agent in fish. Further testing and validation is needed since there may be species differences in the behavioural and physiological response to lidocaine. These studies should employ pharmacokinetics to precisely understand drug dynamics linked to their behavioural and physiological effects.

\section{Conclusions}

This study compared a range of analgesic drugs at various doses in a single teleost fish species under the same experimental conditions. Ventilation rate, feeding and activity were all adversely affected by noxious, potentially painful stimulation. Our results demonstrate that ventilation rate and latency to resume feeding could both be used to assess the response to injurious stimuli in trout, and possibly other teleost fish.

All three drugs demonstrated some beneficial effects in noxiously treated fish. However, lidocaine administered at $1.0 \mathrm{mg}$ per fish produced no side effects and was the most effective at alleviating adverse responses to the acetic acid administration. The choice of lidocaine as an analgesic agent would be practical for use during routine procedures such as tagging. Further research on topical lidocaine spray or cream could also prove beneficial: for example, in the removal of hooks during catch-and-release angling (Tennant, 2005). It is possible that both buprenorphine and carprofen may be of use in different circumstances, when injuries are of a more chronic nature: for example, following surgery or as part of the treatment protocol in disease conditions that might be considered to cause pain in valuable ornamental species. However, these drugs were not particularly effective in the acute pain tests in the present study and resulted in unwanted side-effects which may confound experimental studies.

Further work is necessary to reliably assess the efficacy of analgesic drugs on a variety of fish species as studies have shown species specific behavioural responses to noxious stimuli (Reilly et al., 2008a) and different responses to analgesics including pharmacokinetics (Davis et al., 2006; Newby et al., 2006). Research targeting species that are subject to invasive laboratory experiments would be the first step in developing more reliable and valid analgesic protocols in fish. 


\section{Acknowledgements}

We are grateful to UFAW for funding LS and CRM and to Jon Banks, Ashley Frost and Gregor Govan for technical assistance.

\section{References}

Ashley, P.J., 2007. Fish welfare: current issues in aquaculture. Appl. Anim. Behav. Sci. 104, 199-235.

Ashley, P.J., Ringrose, S., Edwards, K.L., Wallington, E., McCrohan, C.R. Sneddon, L.U., 2009. Effect of noxious stimulation upon antipredator responses and dominance status in rainbow trout. Anim. Behav. 77,403-410.

Ashley, P.J., Sneddon, L.U., McCrohan, C.R., 2006. Properties of corneal receptors in a teleost fish. Neurosci. Lett. 410, 165-168.

Ashley, P.J., Sneddon, L.U., McCrohan, C.R., 2007. Nociception in fish: stimulus-response properties of receptors on the head of trout Oncorhynchus mykiss. Brain Res. 1166, 47-54.

Bateson, P., 1991. Assessment of pain in animals. Anim. Behav. 42, 827-839.

Bernier, N.J., 2006. The corticotropin-releasing factor system as a mediator of the appetite-suppressing effects of stress in fish. Gen. Comp. Endocrinol. 146, 45-55.

Budsberg, S., 2009. Non-steroidal anti-inflammatory drugs. In: Gaynor, J.S., Muir, W.W. (Eds.), Handbook of Veterinary Pain Management. Elsevier, St. Louis, pp. 183-209.

Carrasco, S., Sumano, H., Navarro-Fierro, R., 1984. The use of lidocainesodium bicarbonate as anaesthetic in fish. Aquaculture 41, 395-398.

Danbury, T.C., Weeks, C.A., Chambers, J.P., Waterman-Pearson, A.E., Kestin, S.C., 2000. Self-selection of the analgesic drug carprofen by lame broiler chickens. Vet. Record 146, 307-311.

Davis, M.R., Mylniczenko, N., Storms, T., Raymond, F., Dunn, J.L., 2006. Evaluation of intramuscular ketoprofen and butorphanol as analgesics in chain dogfish (Scyliorhinus retifer). Zoo Biol. 25, 491-500.

Dunlop, R., Laming, P., 2005. Mechanoreceptive and nociceptive responses in the central nervous system of goldfish (Carassius auratus) and trout (Oncorhynchus mykiss). J. Pain 6, 561-568.

Dunlop, R., Millsopp, S., Laming, P., 2006. Avoidance learning in goldfish (Carassius auratus) and trout (Oncorhynchus mykiss) and implications for pain perception. Appl. Anim. Behav. Sci. 97, 255271.

Fowler, M.E., Miller, R.E. (Eds.), 2003. Zoo and Wild Animal Medicine. , fifth ed. W.B. Saunders Co, Philadelphia.

Gentle, M.J., Hill, F.L., 1987. Oral lesions in the chicken: behavioural responses following nociceptive stimulation. Physiol. Behav. 40, 781-783.

Glennon, A., Jeffs, J. (Eds.), 2001. NOAH Compendium of Data Sheets for Veterinary Products. National Office of Animal Health Ltd, Middlesex. Grant, D., 2006. Pain Management in Small Animals, first ed. Elsevier, Philadelphia. 
Grosser, T., Yusuff, S., Cheskis, E., Pack, M.A., FitzGerald, G.A., 2002. Developmental expression of functional cyclooxygenases in zebrafish. Proc. Natl. Acad. Sci. U.S.A. 99, 8418-8423.

Harms, C.A., Lewbart, G.A., Swanson, C.R., Kishimori, J.M., Boylan, S.M., 2005. Behavioral and clinical pathology changes in koi carp (Cyprinus carpio) subjected to anesthesia and surgery with and without intraoperative analgesics. Comp. Med. 55, 221-226.

Hastein, T., Scarfe, A.D., Lund, V.L., 2005. Science-based assessment of welfare: aquatic animals. OIE Rev. Sci. Tech. 24, 529-547.

Hocking, P.M., Robertson, G.W., Gentle, M.J., 2005. Effects of non-steroidal nti-inflammatory drugs on pain-related behaviour in a model of articular pain in the domestic fowl. Res. Vet. Sci. 78, 69-75.

Iwama, G.K., 2007. The welfare of fish. Dis. Aquat. Organ. 75, 155-158.

Mama, K., 2009. Local anaesthetics. In: Gaynor, J.S., Muir, W.W. (Eds.), Handbook of Veterinary Pain Management. Elsevier, St. Louis, pp. 231-248.

Mayer, J., 2007. Use of behavior analysis to recognize pain in small mammals. Lab Anim. 36, 43-48.

McGeown, D., Danbury, T.C., Waterman-Pearson, A.E., Kestin, S.C., 1999. Effect of carprofen on lameness in broiler chickens. Vet. Rec. 144, 668-671.

Newby, N.C., Gamperl, A.K., Stevens, E.D., 2007. Cardiorespiratory effects and efficacy of morphine sulfate in winter flounder (Pseudopleuronectes americanus). Am. J. Vet. Res. 68, 592-597.

Newby, N.C., Mendonca, P.C., Gamperl, K., Stevens, E.D., 2006. Pharmacokinetics of morphine in fish: winter flounder (Pseudopleuronectes americanus) and seawater-acclimated rainbow trout (Oncorhynchus mykiss). Comp. Biochem. Physiol. C 143, 275-283.

Newby, N.C., Stevens, E.D., 2008. The effects of the acetic acid "pain" test on feeding, swimming, and respiratory responses of rainbow trout (Oncorhynchus mykiss). Appl. Anim. Behav. Sci. 114, 260-269.

Newby, N.C., Wilkie, M.P., Stevens, E.D., 2009. Morphine uptake, disposition, and analgesic efficacy in the common goldfish (Carassius auratus). Can. J. Zool. 87, 388-399.

Nordgreen, J., Garner, J.P., Janczak, A.M., Ranheim, B., Muir, W.M., Horsberg, T.E., 2009. Thermonociception in fish: effects of two different doses of morphine on thermal threshold and post-test behaviour in goldfish (Carassius auratus). Appl. Anim. Behav. Sci. 119, 101-107.

Overli, O., Harris, C.A., Winberg, S., 1999. Short-term effects of fights for social dominance and the establishment of dominant-subordinate relationships on brain monoamines and cortisol in rainbow trout. Brain Behav. Evol. 54, 263-275.

Papich, M.G., 2007. Saunders Handbook of Veterinary Drugs, second ed. Elsevier, St. Louis.

Park, I.S., Park, M.O., Hur, J.W., Kim, D.S., Chang, Y.J., Kim, Y.J., Park, J.Y., Johnson, S.C., 2009. Anaesthetic effects of lidocaine-hydrochloride on water parameters in simulated transport experiment of juvenile winter flounder, Pleuronectes americanus. Aquaculture 294, 76-79.

Pottinger, T.G., Carrick, T.R., 2001. Stress responsiveness affects dominant/subordinate relationships in rainbow trout. Horm. Behav. 40, 419-427. 
Rang, H.P., Dale, M.M., Ritter, J.M., Flower, R., 2007. Rang and Dale's Pharmacology, sixth ed. Elsevier, Churchill Livingstone.

Reilly, S.C., Quinn, J.P., Cossins, A.R., Sneddon, L.U., 2008a. Behavioural analysis of a nociceptive event in fish: Comparisons between three species demonstrate specific responses. Appl. Anim. Behav. Sci. 114, 248-259.

Reilly, S.C., Quinn, J.P., Cossins, A.R., Sneddon, L.U., 2008b. Novel candidate genes identified in the brain during nociception in common carp (Cyprinus carpio) and rainbow trout (Oncorhynchus mykiss). Neurosci. Lett. 437, 135-138.

Rose, J.D., 2002. The neurobehavioral nature of fishes and the question of awareness and pain. Rev. Fisheries Sci. 10, 1-38.

Roughan, J.V., Flecknell, P.A., 2000. Effects of surgery and analgesic administration on spontaneous behaviour in singly housed rats. Res. Vet. Sci. 69, 283-288.

Rutherford, K.M.D., 2002. Assessing pain in animals. Anim. Welf. 11, 31-53.

Sneddon, L.U., 2002. Anatomical and electrophysiological analysis of the trigeminal nerve in a teleost fish, Oncorhynchus mykiss. Neurosci. Lett. 319, 167-171.

Sneddon, L.U., 2003a. The evidence for pain in fish: the use of morphine as an analgesic. Appl. Anim. Behav. Sci. 83, 153-162.

Sneddon, L.U., 2003b. Trigeminal somatosensory innervation of the head of a teleost fish with particular reference to nociception. Brain Res. 972, 44-52.

Sneddon, L.U., 2004. Pain perception in fish. Fish Farmer, 8-11.

Sneddon, L.U., 2009. Pain and distress in fish. ILAR 50, 338-342.

Sneddon, L.U., Braithwaite, V.A., Gentle, M.J., 2003. Novel object test: examining nociception and fear in the rainbow trout. J. Pain 4, 431-440.

Tennant, B., 2005. BSAVA Small Animal Formulary, fifth ed. British Small Animal Veterinary Association, Gloucester.

Teraoka, H., Kubota, A., Dong, W., Kawai, Y., Yamazaki, K., Mori, C.,Harada, Y., Peterson, R.E., Hiraga, T., 2009. Role of the cyclooxygenase 2-thromboxane pathway in 2,3,7,8-tetrachlorodibenzo-pdioxininduced decrease in mesencephalic vein blood flow in the zebrafish embryo. Toxicol. Appl. Pharmacol. 234, 33-40.

Thomson, J.T, Watts, P.C., Pottinger, T.G., Sneddon, L.U., 2011. Physiological and genetic correlates of boldness: characterising the mechanisms of behavioural variation in rainbow trout, Oncorhynchus mykiss. Horm. Behav. 59, 67-74.

Underwood, W.J., 2002. Pain and distress in agricultural animals. J. Am. Vet. Med. Assoc. 221, 208-211.

Wagner, A.E., 2009. Opioids. In: Gaynor, J.S., Muir, W.M. (Eds.), Handbook of Veterinary Pain Management. Elsevier, St. Louis, pp. 163-182. 
Walker, K.A., Horning, M., Mellish, J.A.E., Weary, D.M., 2009. Behavioural responses of juvenile Steller sea lions to abdominal surgery: developing an assessment of post-operative pain. Appl. Anim. Behav. Sci. 120, 201-207.

Wendelaar Bonga, S.E., 1997. The stress response in fish. Physiol. Rev. 77, 591-625. 